\section{A safe return to sport and the right to play during COVID-19}

In 2018, the World Health Organization (WHO) launched a global action plan targeting a $15 \%$ reduction, by 2030 , in insufficient physical activity among adolescents. ${ }^{1}$ This initiative was prompted by the discovery that $80 \%$ of youth were not meeting recommendations for daily physical activity. ${ }^{1}$ Accordingly, the WHO called for an urgent "scaling-up" of programs aimed at increasing physical activity and reducing screen time. ${ }^{1}$ Unfortunately, the coronavirus disease 2019 (COVID-19) pandemic has thwarted these efforts. Surveys of 2426 children from Shanghai, China, showed a reduction in physical activity of 7 hours per week and a corresponding increase in screen time of 30 hours per week, when comparing activities before and after implementation of pandemic restrictions. ${ }^{2}$ The implications are dire, because prolonged screen time has been linked to depression and anxiety among youth. ${ }^{3}$ In fact, $64 \%$ of teenagers surveyed in a national youth development organization in the United States indicated that COVID-19 will have a lasting effect on their generation's mental health. ${ }^{4}$ Public health measures must therefore balance the effects of pandemic restrictions against the risks of viral transmission among children. ${ }^{5}$

Chanchlani and colleagues ${ }^{5}$ highlighted the need for data collection processes, to help determine whether severe acute respiratory syndrome coronavirus 2 is locally contracted in youth groups and ascertain how viral transmission affects homes and communities. To this end, Swim Alberta performed a retrospective analysis of data collected from 5873 registered swimmers who participated in swimming cohorts from July to November 2020. Summer data (collected from July to August 2020) were analyzed separately, to account for the potential impact of school closures on COVID-19 infection rates. Aggregate data from 5447 of 5873 registered swimmers (93\%), representing 223324 swimming hours, were included. Most (86\%) cohort participants were aged 18 years or younger, with a female preponderance (59\%). Among 332 swimming cohorts, there were 14 incident cases of COVID-19; 13 cases were reported from September to November 2020, and 1 case was reported during the summer months. There were no reported cases of COVID-19 transmission from swimmer to swimmer, swimmer to coach, or coach to swimmer.

The retrospective nature of this analysis and self-report of COVID-19 status are obvious limitations. It is also unclear whether the low rates of infection $(0.26 \%)$ reflect the efficacy of the cohort model or the protective effects of a chlorinated environment. This latter aspect - a chlorinated or similarly sanitized environment - itself warrants further investigation. Prospective studies investigating both the risk of viral transmission in the cohort model and protective effects of pool settings are needed.

The indirect effects of COVID-19 threaten the physical, social and mental health of youth. ${ }^{5}$ Efforts to mitigate the "collateral damage" caused by pandemic control measures should focus on the safe return to sports and recreational activities. A physically active lifestyle improves cardiorespiratory and muscular fitness, promotes cognitive development and enhances prosocial behaviour in children, with benefits that carry forward into adulthood. ${ }^{1}$ Data-informed decisionmaking and strong political actions are needed. Policies should be aligned with the WHO global action plan, nurture foundational physical literacy and protect the right to play. ${ }^{1}$

\section{Fiona E. Costello MD}

Physician, Departments of Clinical Neurosciences and Surgery, Cumming School of Medicine, University of Calgary, Calgary, Alta.

\section{Keltie Duggan MD}

Physician, Department of Family

Medicine, Cumming School of Medicine, University of Calgary, Calgary, Alta.

\section{Eddy Lang MD}

Physician, Department of Emergency Medicine, Cumming School of Medicine, University of Calgary, Calgary, Alta.

\section{Stephen Norris PhD}

Performance technical director, Mount Royal University; Swim Alberta, Calgary, Alta.

Cite as: CMAJ 2021 February 22;193:E291. doi: $10.1503 / \mathrm{cmaj} .78105$

\section{References}

1. Guthold R, Stevens RA, Riley LM, et al. Global trends in insufficient physical activity among adolescents: a pooled analysis of 298 populationbased surveys with 1.6 million participants. Lancet Child Adolesc Health 2020;4:23-35.

2. Xiang M, Zhang Z, Kuwahara K. Impact of COVID19 pandemic on children and adolescents' lifestyle behavior larger than expected. Prog Cardiovasc Dis 2020;63:531-2.

3. Xie X, Xue Q, Zhou Y, et al. Mental health status among children in home confinement during the coronavirus disease 2019 outbreak in Hubei Province, China. JAMA Pediatr 2020;174:898-900.

4. 4-H youth mental health survey [report]. Chevy Chase, MD: National 4-H Council; 2020. Available: 4-h.org/about/research/\#!healthy-living (accessed on 2020 June 20).

5. Chanchlani N, Buchanan F, Gill PJ. Addressing the indirect effects of COVID-19 on the health of children and young people. CMAJ 2020;192:E921-7.

\section{Competing interests: None declared.}

Content licence: This is an Open Access article distributed in accordance with the terms of the Creative Commons Attribution (CC BY-NC-ND 4.0) licence, which permits use, distribution and reproduction in any medium, provided that the original publication is properly cited, the use is noncommercial (i.e., research or educational use), and no modifications or adaptations are made. See: https://creativecommons. org/licenses/by-nc-nd/4.0/ 